This item was submitted to Loughborough's Research Repository by the author.

Items in Figshare are protected by copyright, with all rights reserved, unless otherwise indicated.

\title{
Re-presenting the Paralympics: (contested) philosophies, production practices and the hypervisibility of disability
}

PLEASE CITE THE PUBLISHED VERSION

https://doi.org/10.1177/0163443718799399

\section{PUBLISHER}

SAGE Publications $@$ The Authors

\section{VERSION}

AM (Accepted Manuscript)

\section{PUBLISHER STATEMENT}

This work is made available according to the conditions of the Creative Commons Attribution-NonCommercialNoDerivatives 4.0 International (CC BY-NC-ND 4.0) licence. Full details of this licence are available at: https://creativecommons.org/licenses/by-nc-nd/4.0/

\section{LICENCE}

CC BY-NC-ND 4.0

\section{REPOSITORY RECORD}

Pullen, Emma, Daniel Jackson, Michael Silk, and Richard Scullion. 2018. "Re-presenting the Paralympics: (contested) Philosophies, Production Practices and the Hypervisibility of Disability". Loughborough University. https://hdl.handle.net/2134/37614. 
Producing the Paralympics: (Contested) Philosophies, Production Practices and the Cultural Politics of the Hyper-Visibility of Disability

To cite:

Pullen, E; Jackson D; Silk M. 2018. Producing the Paralympics: (Contested) Philosophies, Production Practices and the Cultural Politics of the Hyper-Visibility of Disability. Media, Culture \& Society. DOI: 10.1177/0163443718799399

\begin{abstract}
Studies that have engaged para-sport broadcasting, particularly through a narrative lens, have almost exclusively relied on textual and/or content analysis of the Paralympic Games as the source of cultural critique. We know far less about the decisions taken inside Paralympic broadcasters that have led to such representations. In this study - based on interviews with senior production and promotion staff at the UK's Paralympic broadcaster, Channel 4 - we provide the first detailed examination of mediated para-sport from this vantage point. We explore the use of promotional devices such as athletes' backstories - the "Hollywood treatment" - to both hook audiences and serve as a vehicle for achieving its social enterprise mandate to change public attitudes toward disability. In so doing, we reveal myriad tensions that coalesce around representing the Paralympics; with respect to the efforts made to balance the competing goals of key stakeholders and a stated desire to make the Paralympics both a commercial and socially progressive success.
\end{abstract}

Key words: Paralympics; Disability; Production; Representation; Broadcasting

The labour process - as it articulates with political, economic, technological and cultural conditionsinvolved in televised sport production remains in the scholarly wilderness (see e.g. Johnson, 1986; McRobbie, 1996),. Whilst there have been advances in knowledge from those who have focussed on the practices of televised sport professionals (e.g. Gee and Leberman, 2011; Liang, 2013; MacNeill, 1996; Author removed 2002; Author removed et al., 2000), our scholarly understandings are, for the most part, predicated on assumptions drawn from textual readings. Production itself has been all but banished from view, whilst the rationale of cultural production, the conditions that impinge on production, and the place 
and thoughts of cultural producers (and academic debate with these cultural workers), remains to all intents and purposes, neglected (cf. Ferguson and Golding, 1997; Author removed, 2002; Whannel, 2013).

Technological innovations, infrastructure availability, normative production practices, the legitimization of media narratives for capital accumulation (advertising, sponsorship revenues), preferred narratives of nation, and a neoliberal corporeal aesthetic (see e.g. Jhally, 1989) have provided insights into, and explanations for, televised sport production practices (see e.g. MacNeill, 1996; Whannel, 1992). Yet, important questions remain over how such normative/'accepted' practices, or specific 'ways of doing', articulate with productions predicated on marginalised groups and a context in which stigma is evident. With the intention of beginning to fill this scholarly lacuna, this study offers a window into the production practices of UK broadcaster Channel 4 who have, since 2012, been the official broadcaster (in the UK) of the Paralympics. We would aver that going 'behind the scenes' of Paralympic broadcasting, providing the first empirical knowledge base centred on producing Parasport and the representation of disability, provides particularly important insights given 'few researchers have questioned the assumptions ... or (outside of media content analysis) examined it [disability] empirically' (Berger, 2008: 648). Within this article then, by focusing on the practices, intentions and decisions of Channel 4, an attempt is made to uncover which meanings of para-sport bodies circulate and which are masked or excluded. By going beyond textual critique, we uncover the complexities and nuances that form the context for representations of disability, the important role of promotional devices — such as athlete back stories-to 'hook' audiences, the broadcasters social enterprise ambitions centred on changing public attitudes toward disability, and inherent tensions and negotiations with various Paralympic stakeholders.

\section{The Mediation of Disability}

Disability studies has tended to neglect questions of culture, representation, and meaning, and ignored individual and collective lived experience (Shakespeare and Watson, 1997). Mediated representations of disability have historically been largely negative and drawn on a limited number of stereotypes, in particular those of: helpless, passive victims who are dependent on others; as vulnerable and pitiable and childlike dependents; as 'supercrips' with an emphasis on inspirational stories of determination and 
personal courage to overcome adversity; as less than human, often presented as villain, freak shows, or exotic; or, defined by their disability rather than other aspects of their identity, presented as unable to participate fully in everyday life (Ellis 2008; Author removed et al., 2015; Shakespeare 1999). Indeed, Briant et al., (2013) suggest that there has been a marked and relatively recent shift in the mediation of disability from sympathetic towards positioning the disabled as a new folk devil (fraudulent, not disabled, benefit scroungers) and less deserving (especially regarding mental health over physical disabilities, with invisible impairments where the severity cannot be visually demonstrated being most demonised). This is especially the case amidst a context (at least in the UK) of benefits cuts for the disabled and increasingly polarized labour markets.

Given this context, there remain pressing concerns about everyday lives for people with disabilities and with respect to public attitudes/perceptions towards disability (Goodley, 2011). Indeed, according to the World Health Organisation (2011), the lived experiences of many people with disabilities are linked to negative attitudes, beliefs and prejudices that constitute a multitude of barriers to education, employment and participation in everyday life (see also, Dear et al., 1997). Access to employment is a particularly pronounced issue facing people with disabilities despite the passing of legislation and policy focused on disability inclusion in the workplace (Barnes and Mercer, 2005). This is particularly the case in a visual medium such as television where a 'preferred' body politic holds significant capital, and where disabled people have been historically underrepresented (Ellis, 2016); in the UK, only 3\% of employees across the five main broadcaster networks are disabled compared to $18 \%$ of the UK population (Ofcom, 2017a). Under the 2003 Communications Act, the communications regulator in the UK, Ofcom, is required to promote equality between men and women, people of different racial groups, and importantly for this paper, for disabled people. Ofcom's (2017b) guidance and recommendations requires broadcasters to make arrangements to promote diversity, and strongly encourages moving beyond short-term initiatives so as to embed diversity and equal opportunities within long-term planning (not just for employees, but for freelancers and production companies who work for them). This regulatory environment is important for understanding what Paralympic stories were told and about what (and by whom), which meanings were given prominence and what cultural resources were made available and to whom (McRobbie, 1996). Given 
the important role of mediation in the construction of disability (Barnes and Mercer, 2010; Ellis, 2008), we turn our attention to a cultural form — parasport—in which disability, albeit for ephemeral moments during major competitions, is heightened, if not, hyper-visible.

\section{The Mediation of Parasport}

Given mediated sports are important constituents of popular culture and forms through which political discourse can be traced (Whannel, 2013), it is paramount that we pay careful attention to the modes of Paralympic representation, their possible implications, and their potential impact (Silva and Howe, 2012) However, the media representation of athletes with disabilities has not been extensively studied, described as being in its infancy (Pappous et. al., 2011; Ellis and Goggin, 2015). Further, UK think-tank, DEMOS, suggested the majority of people with disabilities remain untouched by the Paralympics, calling for more joined-up evidence based research to address the cultural legacy of Paralympic sport, disabled people and their role in cultural life.

In a commercial media culture that celebrates the pleasure derived from cultivated and enhanced embodiment (healthy, fit, sexual, hetero-normative, attractive), the principal challenge to the production of an idealized aesthetic comes from ageing, death \& disability (Turner, 1996). This is perhaps exacerbated in sport; sports journalists - whose professional habitus is to produce pictures of perfect, (gendered) idealised neoliberal bodies (Cooky \& Messner, 2013) — have, it is argued, reacted negatively towards disability (see e.g. Schantz and Gilbert, 2001). Indeed, the Paralympic Games itself has transitioned from pastime to global spectacle (Howe, 2008); accompanied by the need for advertising and sponsorship revenues, celebrity performers, and the dictates of the mega-event marketplace. Thus, and at this juncture, as the profile of Paralympics/para-athletes has increased, Paralympic stakeholders possess a variety of competing, albeit not mutually exclusive, tensions regarding the ways in which sport and disability are and/or should be represented via the Paralympic Games. While some stakeholders position the Games as an elite sports event, others prefer to highlight the role disability plays in giving meaning and value to disabled bodies (Purdue and Howe, 2013).

Those scholars investigating Paralympic and para-sport coverage (e.g. Beacom et al., 2016; Bruce, 2014; 
Cherney et al., 2015; Howe, 2012; Pappous et al. 2011, Purdue and Howe, 2013), have pointed to the marginalization or inferiority of elite disabled athletes, comparative lack of interest, and the reinforcement of medicalised, individualised and stereotypical understandings of disability, often presenting disabled athletes as having triumphed over adversity (Cherney et. al., 2015; Hardin et. al., 2004). In particular, Paralympic coverage has been critiqued for a dominant narrative of heroic achievement and disability bravely overcome, and as non-representative of everyday life with disability, suffering, pain and loneliness (DEMOS, 2013).

Particular attention, in part relational to the IPC's own classification system (see Howe, 2008), has been paid to how coverage tends to reinforce established hierarchies of disability. Based on hierarchies of acceptance or acceptance hierarchies (see Westbrook et. al., 1993), these are structures of preferences among the general population regarding people with disabilities or other perceived differences. In Paralympic coverage such hierarchies have been clearly manifest, especially through a technocratic ideology that privileges cyborgified athlete-prosthetic hybrids (see Silva and Howe, 2012) often in the guise of the supercrip or superhuman. Whilst the prefix 'super'-superhuman, superathlete, supercripoffers apparent positive narratives of people who 'overcome' their own personal tragedy through courage, dedication and hard work (Ellis and Goggin, 2015; Hardin and Hardin, 2004; Silva and Howe 2012) it implies a stereotyping process that requires an individual to fight against his/her impairment in order to conquer it and achieve unlikely success (Berger, 2008). In this way, 'super' narratives can serve to distance and disconnect athletes from the lives and perceived lives, of many (non-athlete) people with disabilities (Silva and Howe, 2012).

Relative tensions inherent within the IPC regarding representations of, and meanings ascribed to, Paralympians, were perhaps exacerbated by the entry of Channel 4 (C4) in the UK as Paralympic rights holders in 2012 (see Walsh, 2015). C4 brought a level of ambition for Paralympic broadcasting that was, in the words of their former Disability Executive Alison Walsh, at 'a whole new level' from previous events; the ambition centring on creating a nation 'at ease with disability' (Walsh, 2015:27). Under the auspices of broadcasting regulation in the UK, this included fostering both on- and off-screen disability talent by recruiting presentation and production staff with disabilities, giving unprecedented exposure to para sport 
(a 400\% increase in coverage from the 2008 Beijing Paralympic Games), and pursuing a "no-holds-barred approach to portrayal of disabled people" (Walsh, 2015: 49).

C4's engagement with the Paralympics offers a distinct contextual moment from which to understand the representation of disability. This is a moment defined by the increased commodification of the Paralympic spectacle, a heightened, if fleeting, visibility of disability on television-which we term the hypervisibility of disability-and oft (although far from exclusively) historically embedded stereotypical representations of disability. This maelstrom provides a telling contextual moment from which to address representations of disability, especially in its most (hyper-)visible vehicle, the Paralympics.

\section{Methodology}

To enable a robust empirical knowledge base centred on producing para-sport and representations of disability, our methodological approach was integrative, bringing together document analysis (e.g. promotional materials, broadcast plans, websites), elite interviews, and textual analysis. For the most part, our analysis in this paper is based on in-depth elite interviews with 23 senior production staff (between February and March, 2017), including commissioning editors, creative diversity managers, senior marketing and PR executives, stakeholder relations professionals, TV presenters, executive producers and pundits from $\mathrm{C} 4$ and their commissioned broadcast partners. These interviews were of import-and form the basis for much of the analysis herein — given the position and influence of participants within either $\mathrm{C} 4$ or their partners, the knowledge these elites possess, and the exclusive privileges they are afforded (Delaney, 2007; Rice, 2010). Whilst elite interviewing is relatively rare and elites understudied (given problems associated with access and the willingness to divulge data [Mikecz, 2012] and the sample relatively small and purposive (given the nature of their 'elite status'), we conducted interviews with these participants on multiple occasions and have returned to share initial results and interpretations - - this in and of itself acted as a source of additional data. The elite interviews focused on the insight they possessed into Paralympic representations and their experiences of producing and promoting parasport (from London 2012 to Rio 2016) from whichever vantage point they held based on their particular profession. 
Given the nature of an elite and powerful group of interviewees, and the crucial balance with institutional research ethics, all names and job titles have been removed. Whilst we set the criteria for the types of participants we required for the study, $\mathrm{C} 4$ led the recruitment process; access was thus a process of negotiation (Mikecz, 2012) common in elite interviewing. On balance, and following Delaney (2007), the use of elite interviews provided a rich data set that offered us a rare opportunity to understand the worldviews of those who have significant influence in decisions that influence the production of parasport coverage. Audio recordings of interview data were analysed through Johnson et. al.'s (2004) four dialogic moments of interpretation, allowing for the contextual development of key instances and themes through close reading or 'meaning condensation' (Coffey and Atkinson, 1996). Such an approach provided opportunity throughout the analysis for us to socially situate the research (and researchers) and 'work the hyphen' between private and public (Fine et al., 1994).

\section{'A Total Eclipse of the Sun': Statutory Remit \& the Social Change 'Journey'}

Underpinning the broadcast decisions of the Paralympic Games was the recognition of a ' $\mathrm{C} 4$ way' or philosophy of practice, an approach that dovetails with the regulatory broadcast environment in the UK. C4 operates under a statutory remit as a sustainable social enterprise with a mandate that includes stimulating debate and education, promoting innovation and fostering new talent, reflecting cultural diversity, and inspiring change through high-quality and innovative content that challenges the status quo (see https://www.channel4.com/corporate/about-4/who-we-are/what-is-channel-4). The 'C4 way' was described by one senior executive as 'doing it first ... being diverse' and C4 viewed the 2012 Paralympics as an opportunity to translate this philosophy into production practices that 'inspired change and championed difference.' Indeed, the perceived 'fit' between the Paralympics and C4's public service remit was near perfect, as a senior executive explains:

The values of the Paralympic Movement and the values of Channel 4, they come together in almost a total eclipse of the sun ... Be different, stand up to diversity, represent an alternative point of view, 
champion young people, champion new talent. You can see how the Paralympics is just a bull's eye on many of those things.

C4's broadcasting of the 2012 Paralympic Games acted as a showcase of, and a commitment toward, the 'C4 way.' The single biggest project in the broadcaster's history, the stated aim was to change dominant media perceptions of disability; 'the slightly apologetic attitude towards showing disabled people whether they're sportspeople or not, generally on television' (senior executive). Previous Paralympic broadcasters were deemed, by participants, as too 'conservative'; their Paralympic coverage a manifestation of an apologetic positioning of disability (Briant et al., 2013). This was apparent, for example, in notably fewer hours of coverage for the Paralympics (compared to the Olympic Games) and production aesthetics and practices that often saw the camera 'shying away from the impairment' (senior executive).

C4 were deeply cognizant of these underpinning industry practices and cultural assumptions, that they felt reinforced marginalisation within mainstream media products:

Fundamentally the public will never take disability sport as seriously or feel about it as passionately on the same scale as able bodied sport ... because people instinctively and unconsciously think that a disabled person is not going to be able to perform to the same level as an able bodied person and therefore the sport is never going to be as good. I think that may or may not be true, but when your job is to be the one that is innovative, alternative, challenging, that was like a red rag to a bull to us ... from that moment on, I think it made us even more focused ... to get the public to see what we could see you had to shake things up and be quite confrontational and be quite in-your-face but authentic (senior executive, our emphasis).

Congruent with academic work (e.g. Silva \& Howe, 2012; Howe, 2011; Pappous et al., 2011) and indeed wider societal perceptions of disability that have tended to point to the marginalisation of para-sport itself, alongside the practice and status of para-sport mediation, the account above takes as its starting point a direct comparison to able bodied norms and able-bodied sporting productions. The starting point is the 
dominant assumption of the incompatibility or disjuncture of the disabled body with the structural and material practices of able-bodied an elite sport complex structured by a discourse of ableism. Whilst this standpoint may not in and of itself be overly useful, C4 felt that a 'reframing' of Paralympic coverage was required, one that challenged dominant able-bodied production techniques, legitimised it as an elite sporting event, and stimulated audience interest. To achieve these ambitions, $\mathrm{C} 4$ took a significant step change in the marketing and broadcasting of the games, in an effort to differentiate the Paralympic media product within the media sport marketplace, and to break from the perceived (aesthetic) 'misfit' of the disabled body and the elite sport context. Of central importance was a form of marketing that utilised athlete backstories as the point of distinction. In so doing, some of these stories centralised (rather than erased) disability - they were described by one interviewee as 'confrontational'-but were emplaced within a wider narrative of sporting success, and thus were seen as an 'authentic' technique that could serve to both legitimise elite sport and serve as a point of difference. Such an approach was a pathway to connect to audiences, to 'normalise' disability (senior executive) and provide a provocative vehicle to challenge societal perceptions of disability:

To get the public interested you have to go through people's stories to really appreciate the amazing thing that they are doing on the track ... there's no getting away from the fact that a lot of the Paralympic athletes have got much more interesting and incredible backstories than able bodied athletes, why should we not tell those stories as well? Portray them, yes, as incredible athletes and that's the first thing we want you to see is their incredible athletic ability but we weren't also going to shy away from the fact that there is backstory of somebody having to overcome an adverse situation or come to terms with disability, we wanted to tell the human stories as well; so it's humanising people the whole way through but also reinforcing that these are not just any old people (senior executive).

This extract is instructive in a number of ways. The emphasis on overcoming adversity plays into stereotypical narratives of heroism and triumph that have previously been associated with the supercrip narrative (Cherney et. al., 2015; Hardin et. al., 2004; Howe, 2012; Purdue and Howe, 2013). At the same 
time, perhaps laudable efforts to 'humanise' parasport athletes may have worked to 'other' through fixing on impairment as the signifier of difference, thereby reinforcing dominant ableist logics. As such, in an effort to stimulate audience interest (and thereby satisfy commercial imperatives) and take the audience on a journey toward changing social attitudes toward disability, the fixation on impairment as difference may have actually served to dehumanise para-sport athletes. Indeed, to some extent we can see an emergent dichotomy between 'incredible athlete' and 'having to overcome an adverse situation'; a binary emphasised through the apparent distinction made between the story of being a Paralympian and the story of being disabled structured by a broader narrative of difference akin to the 'extraordinary' or 'freak' body of typical representational modes. Most markedly and perhaps most important in terms of production decision-making and the circulation of meanings ascribed to parasport athletes through mediation, the backstory most denoting difference - the disability itself- held more currency as an effective marketing tool (than being an athlete) and thus served as the rhetorical divide deployed to capture, and connect with, the emotive sensibilities of presumed audiences. This does less to break the elite sport / disability dichotomy, but rather, serves the industry apparatus of 'storying' difference that the nonnormative body disabled or other - is called to do in social contexts and for a consuming audience.

\section{Giving it the Hollywood Treatment: the hyper-visibility of disability}

Whilst the use of backstories perpetuate many of the criticisms levelled against representations of disability (e.g. 'sensationalizing' personal interest stories as a 'hook' for audience, see Purdue and Howe, 2013), interviewees were aware of the challenges in attracting audience interest to parasport coverage and highly reflective about their current approach. Indeed, interviewees felt that their approach was an important 'stepping stone' on a pathway toward achieving their wider statutory remit. In this regard backstories served a dual function with an inherent dialectic logic; the need to 'other'-through the promotion of personal, and often sensationalised, human interest stories - acted as the pathway to inspiring populations and achieving greater, social good. This deliberate tension is illustrated by one senior executive: 
It is an endless argument and one that sits at the very heart of how we broadcast as a channel about the Games, it's a question of the chicken and the egg. From a broadcast point of view we're interested in the Paralympics because you have got, say London there were 4,200 athletes I think. There are 4,200 epic stories of overcoming adversity that can give a lot people around the country huge motivation and inspiration. But also from a broadcaster [perspective], a brutally honest one, it is interesting because their stories are interesting to hear ... it's a natural curiosity and the entire country wants to know that, but of course as a broadcaster we are obliged to cover what the audience are going to be interested in, which is that [disability] at the moment ... I wish we could get to a point where alright fine, 'you had a little accident. Whatever. You are in a wheelchair but what are you doing now?' ... You see, we are not there yet (emphasis added).

The need to take audiences on a journey came from a perception that audiences are not yet 'ready' to simply 'accept' disability as portrayed through a Paralympic lens. Simply 'seeing' disability would not, it was felt, enable audiences to understand / come to terms with disability, nor provide the 'hook' to keep audiences watching. Instead, a decision was made to show disability differently by giving it the 'Hollywood treatment':

If you have been in some terrible accident or some terrible war zone and you've got scarring ... this is not a tea party, let's see it. Actually most people will be able to deal with the reality of that, particularly if you do something that's never been done before ... it's giving it the Hollywood treatment and giving it attitude and a sexiness that isn't normally associated with that side of life (senior executive, our emphasis).

Giving it attitude, a 'sexiness', offered more than just seeing. There was a need to narrate, to render marked difference - disability-(hyper-)visible. The intent was to make, as one senior executive suggested, disability 'popular', to 'create characters' with which the audience could 'empathise' and therefore stimulate audience expectation both ideologically and materially in the narration of the marked body differently. Such decisions were not always uncontested and were the subject of debate amongst senior 
staff and with Paralympic stakeholders. To take a telling example, the 2012 promotional campaign 'Meet the Superhumans' (http://www.channel4.com/info/press/news/meet-the-superhumans) integrated footage of elite performance with dramatic footage of how various disabilities might be acquired (this included footage of a bomb exploding in a war, a car crash, and of a baby in a womb suggestive of congenital disabilities). Drawing on a supercrip narrative predicated on inspirational messages of individual success in overcoming impairment (Beacom et al., 2016; Silva \& Howe, 2012), the campaign was widely regarded as a watershed moment given its up-front and dramatic portrayal of disability.

The superhuman promo drew on the historically grounded affinity between para-sport and the military (see e.g. Batts and Andrews, 2011; Crow, 2014) and may have done little to counter criticisms that dominant representations of Parasport tend to focus on certain 'forms' of impairment over others: the most successful supercrips (those who demand the most media attention/are celebrated) are often those who require use of mobility technologies (Howe, 2013) and/or those with less severe forms of impairment who may be deemed as more 'marketable'. However, in contradistinction to DePauw (1997) who suggested Parasport coverage was centred on the (in)visibility of disability in an effort to stress elite athletic competition, and leading to representation of what can be termed the able-disabled (Mitchell and Snyder, 2015), C4's approach is to mark difference and make difference (hyper-)visible. With Purdue and Howe (2013), the contemporary and complex milieu of relations in the Paralympic community between stakeholder groups and invested 'voices' will ensure continued debate on the apparent contradictions between the legitimisation of the Paralympic games as 'elite' sport and production decision and practices. Indeed, for $\mathrm{C} 4$, the apparent tension appears to be negotiating a focus on the ability of performance with the subordination of bodies deemed severely impaired and dis-abled.

\section{Creative Tensions: A contested pathway to Paralympic Representation}

Despite alignment between the Paralympic ethos and C4's remit, tensions related to commercialisation, spectacle, and elite sport performance have, and continue to, define C4's relationship with key stakeholders. The International Paralympic Committee (IPC) and British Paralympic Association (BPA), 
for example, had both previously pursued agendas squarely predicated on showcasing elite sport. The BPA for example, were concerned about C4's broadcast portfolio and innovative plans to 'do things differently'; as one senior executive explained:

LOCOG (London Organising Committee of the Olympic and Paralympic Games) made it very clear to me that it was extremely important that Channel 4 developed very quickly a good relationship with the BPA ... indeed the following morning, I rang up and said can I come round and say hello. So I went round to see the [name] who was then [role] ... and it would be fair to say that our meeting was not unfriendly but a little frosty. Because they don't know us at all, I think they felt that it was tough on the BBC, with whom they had worked [previously] and [whom] had supported Paralympic sport. And 'who are you people, Jonny-come-latelies to the party and are you going to do a Big Brother, are you going to not treat my team seriously, are you going to devalue this?

Indeed, there was particular concern over the 'Hollywood treatment':

Our Paralympic coverage is on the edge of what the IPC and the BPA would have wanted, and they didn't realise what they wanted until we had done it. I think there's almost a bit of creative tension about ... because one of the big things we had a big tussle with them about ... is whether you should tell the backstories of the athletes (senior executive).

Whilst one senior executive described the relationship between the IPC, the BPA and C4 as 'always in tension', C4 saw themselves in the role of advocate, as a 'cultural change agent' in the management of stakeholder relationships. Accordingly, the language of 'journey' was employed to describe their efforts in regard to relations with the Paralympic governing bodies. This tension was perhaps particularly acute for athletes, especially given para athletes' overwhelmingly want to be treated as elite athletes (Hardin and Hardin, 2008). Framed by their statutory remit and Ofcom regulation and guidance, part of C4s commitment to the Paralympics was to ensure that people with disabilities were not just the focus of the lens; rather, they made a commitment to nurture new and existing talent across the spectrum of production. 
In so doing, they created multiple opportunities for production staff with disabilities and created inclusive campaigns for advertisers; their most laudable legacy perhaps being the training and development of a variety of television personnel with disabilities. Indeed, C4 employ the highest proportion (11\%) of disabled people compared to other UK broadcasters (Ofcom, 2017a). Whilst this may be a case of aesthetic labour (see Cutcher and Achtel 2017), where employees 'perform' the brand through bodily capital and thereby further reinforcing the C4 brand as 'different', 'diverse', and edgy, it is suggestive of a step toward actively challenging the status quo and institutional labour practices and workplace discrimination off screen. Further, $\mathrm{C} 4$ were committed to ensuring that their presentational component was no different, and developed a number of on-screen presenters (many former parasport athletes) who, at the time of writing, are regular and fixed entities in C4's coverage. For those former athletes (now presenters), the tension inherent in 'the journey' was one that required a process of negotiation:

I had to be convinced about the idea of talking about people's backstories and talking about how people got their disabilities. I suppose if you understand my point of view, I have spent my life talking about my disability, pretty much everyone you meet for the first 20 years of your life, they ask you why are you in a wheelchair or why do have this, at some point that will come up. In my mind, I was kind of tired of it, but what I forgot — and that was maybe my inexperience in making TV—is not everyone has my experience. For many people watching the Paralympics, this will be the first time and those questions will be the questions they will be asking. So I needed to put my experiences to one side and also think about the newcomers. I was convinced very much by Channel 4's thinking, saying that actually we should talk about disability, we should put it out there in the open and we should answer those questions that people will be asking at home (former Paralympian).

The aforementioned 2012 'Meet the Superhumans' campaign was perhaps the epitome of the tensions between $\mathrm{C} 4$ and its stakeholders. As the central framing device showcasing C4's positioning of the Paralympics, it became the anchor point for representation. Powerful and emotive, with high production values, the campaign attempted to both provoke and draw attention to the upcoming Paralympics. The 
finished 'film' may have been slick, the production process may have won industry plaudits, and it might have acted to cement $\mathrm{C} 4$ as the 'home' of the Paralympics; yet getting to this point required sustained engagement, diplomacy and engagement with stakeholder groups. Interviewees spoke particularly about the considerable investment that went into working with disability action groups, charities, and athletes, often through involving them in audience testing of the advertising campaigns:

Some of the stakeholder groups ... were very wary of all of that. [We put in] enormous time and effort briefing people on our plan for the marketing campaign before we started to do it. We knew that we couldn't have stakeholder groups rubbishing it or coming out and being critical or dissing it when they saw it. So we knew we had a job on our hands to persuade them why we were doing what we were doing (senior executive).

There is a breakdown moment in the [Superhumans] film where is it all big and glossy and you see ... the moments where, the car overturns, the bonnet explodes or the mother is told her child is disabled. And then it goes back into the [sporting] action. A lot of people, a lot of disability groups had major issues with that because they thought it was intrusive ... the way we got round the objections and the various representative bodies, was by going to the athletes and going, this is the film and they went 'that is fucking cool' (senior executive).

Despite some para-athletes being utilised as advocates, anxieties remained; C4's bold approach was not universally accepted amongst all stakeholders, some deemed it too controversial and felt it did not accurately reflect the range of acquired/congenital disabilities. C4 understood this as constructive conflict, and the final product was a unique framing device that elevated a parasport spectacle; one that continues to negotiate tensions between commercial success and social change in the framing of disability. Under their remit to foster social change, $\mathrm{C} 4$ have persisted with these broadcast decisions (and indeed it has permeated non-sport programming) with the stated intent to 'get to the humanity of what it is like to be disabled' and maximise 'the emotional engagement with backstories' (senior executive). By 2016, there was a notable shift in the 'speed and the method' of this approach, with promotional campaigns for the Rio Paralympics 
placing 'everyday' people with disabilities alongside elite athletes (https://www.youtube.com/watch?v=IocLkk3aYlk), an increase in on and off screen personnel with disabilities, and backstories featuring athletes in their everyday environments ${ }^{\mathrm{i}}$. Again contested internally, lest it take away a focus from elite sport, interviewees felt that they were in a place by this point in which they were able to not 'just try and confound people's expectations of what a disabled athlete is [but] to try and confound people's expectations of a disabled person' (senior executive).

The 'everyday' in the 2016 promotional campaign (e.g. a double arm amputee holding a baby, flying a plane, working in an office) could well be interpreted as relatively distant from the daily lives of many people with disabilities: a context of benefit cuts, welfare reforms and polarized labour markets (e.g. Briant et al., 2013); although there was certainly a discernible shift-albeit production was still over-determined by Paralympic/ disability hierarchies - herein with respect to the breadth of disabilities showcased relational to 2012. However, the 'journey' points to how C4's perceptions of wider societal attitudes has framed their production choices and how this has shifted over time. Further, it sheds important light on, and raises questions about, which bodies are deemed credible, palatable, accepted and legitimate, and thereby marketable, normalized disabled (sporting) bodies within our contemporary moment (Purdue and Howe, 2013).

\section{Concluding Comments}

Paralympics representations, in the UK at least, exist within a regulated environment that has framed production philosophies, practices and decisions. The 'journey' of Paralympic representation has been largely legitimised through a remit to be different, innovative and push boundaries; values that are clearly embedded within the organisational values of C4 and the craft pride (Stoddart, 1994; Author removed et al., 2000) of production personnel and senior management. Whist this might not be the case outside the UK given the global retreat of public service broadcasting and rising tide of digital narrowcasting and neoliberal deregulation (see Barsamian, 2001; Freedman, 2008), there does seem to exist an institutional isomorphism (cf. DiMaggio \& Powell, 1983; Beckert, 2010) in global Paralympic coverage in which C4 
are positioned at the head of the table. Indeed, and in light of its bold and ambitious approach to para-sport broadcasting, C4 has received widespread praise from Paralympic governing bodies, industry award committees and by the UK public at large (see Walsh, 2015), and is now advising broadcasters across the world on their para-sport production (including the Tokyo 2020 host broadcaster). This palpable shift in Paralympic representations has not been uncontested, and the data in this article are suggestive that the 'journey' for all stakeholders will be continuously negotiated and debated, pointing to the complexities behind decisions over how athletes with disabilities are represented through Paralympic coverage. Of course, this journey is not just for the multiple stakeholders, but for consumers who are the ultimate barometer of C4's remit to 'inspire social change. 'ii

It would be remiss not to return to contextualising C4's Paralympic coverage within its wider disability programming, long-term planning, and employment practices. 2016 was C4's Year of Disability and, in addition to some of the initiatives discussed herein, saw a commitment to focus on providing placements and apprenticeships for people with disabilities. Further, the channel doubled the number of people with disabilities appearing in their biggest shows: Hollyoaks, Gogglebox, The Island, Grand Designs and First Dates, as well as commissioning content that aims to challenge dominant disability discourse, including 'The Undateables', 'Pimped Up Limbs', and 'Disability Daredevils'. Perhaps most significant—not least as it provided the vehicle for C4's primetime Rio 2016 Paralympic coverage-is the satirical, offbeat comedy, The Last Leg, which offered a 'no-holds barred' approach to Paralympic coverage (see Giuffre, 2015). Predicated on the hashtag 'isitok', the show (presented by two comedians with physical impairments and one able-bodied) challenged both dominant discursive framing and the conventions of sport highlights packages ${ }^{\text {iii }}$. Whilst not the focus of this study, this context is of importance given the range and diversity of Paralympic broadcasting speaks to how, at one and the same time, $\mathrm{C} 4$ were simultaneously reinforcing and challenging supercrip narratives. In this respect, C4's on-going journey-with the intent to normalise disability (or more accurately, certain disabilities) — suggest that we will likely require a more layered and nuanced understanding of the supercrip narrative to theoretically comprehend the complexities of C4's Paralympic representations. 
Perhaps the most contested aspect of C4's coverage has been C4's promotional campaigns and the production of athlete backstories. As argued, these not only mark and render disability (hyper-)visible, but they narrate with the intention of popularizing and making disability 'sexy.' We have argued that the creation of characters with which consumers can 'empathize' could serve to normalize certain (cyborgified/ technocratic) bodies (Howe, 2011)—superhumans—yet, could run counter to elite sport agendas. Questions thus remain over those who do not win medals or media acclaim (e.g. athletes with cerebral palsy and severe impairments whose backstories are thereby deemed unsexy, less marketable and media-friendly; unworthy of the 'Hollywood treatment'). Do such athletes become further disempowered and marginalised (dehumanized) by the degree of nature of their impairment (serving instead to reaffirm the normalcy of non-disabled people) (see also Crow, 2014; Howe, 2011; Peers, 2009; Purdue and Howe, 2013)?

Perhaps the key tension herein is in the ways in which Paralympic representations can achieve a social change agenda within social and political structures built on able-bodied norms (Mitchell and Snyder, 2015). Is the 'supercrip' narrative an effective 'emancipatory' device for achieving progressive social change? The data in this paper suggest $\mathrm{C} 4$ see themselves on a long journey toward normalising disability and changing attitudes that stigmatise/'other' bodies that do not conform to ablest discourses. This approach to the Paralympics as a catalyst for eventual progressive social change give C4 'permission' to be bold and attention grabbing without overtly disrupting power relations or becoming a site of resistance. It is an approach that straddles-perhaps avoids - tensions that coalesce around whether varying forms of disabilities can, should, or desire to be normalised, and indeed who has the right to do so? At this juncture, C4 are ultimately creating spectacular broadcasts deemed appropriate for their commercial partners and palatable for (primarily) able-bodied audiences whose life experiences are distant from experiences of living with disability. It would perhaps be unfair to overly critique $\mathrm{C} 4$ for a form of soft or 'organisational paternalism' (Mladenov 2015) in which broadcast decisions could be deemed as marketised citizenship. However, and whilst embracing a civic purpose is not particularly new, the data does suggest an inherent predisposition of 'civic consumerism' that serves to preclude consideration of certain types of possible coverage. Indeed, tensions and negotiations were successfully corralled because the need to construct sporting spectacle was the absolute priority. Sat within broader questions of mediated disability, then, we 
are reminded that mega events are ultimately only that - events - and occupy a fleeting moment of time in the even broader contested terrain of cultural production and reinforcement of ideology. As such, C4s Paralympic representations contain both potential for progressive social change but also the capacity to undermine citizenship through emphasising notions of global consumption over local citizen's rights (Taks 2013). In this respect, the journey toward normalising disability — or certain preferred forms of palatable Paralympic representations - offers the potential for progressive social change, yet at one and the same time, serves to normalise a dominant able-bodied framing via marking disability as 'different'. This is a normalising process from the perspective of those with the power to mediate, a powerful ideological agenda that has the potential to gain cultural and discursive agreement about (acceptable) disabilities and which speak to an individuated, 'responsible' neoliberal mantra that positions the able-disabled as 'normal' whilst othering unproductive and dysfunctional (abject) disabled bodies. Collectively then, and at this

conjunctural moment, Paralympic representations might (ephemerally) render disability hyper-visible, but does so within extant power structures, doing little to shatter dominant discursive disability frames.

\section{References}

Barnes C and Mercer G (2005) Disability, work, and welfare: challenging the social exclusion of disabled people. Work, employment and Society. 19(3) 572-545

Barnes C and Mercer G (2010) Exploring Disability. Cambridge: Polity Press

Barsamian D (2001) The decline and fall of public broadcasting. Cambridge, MA: South End Press. 
Batts C and Andrews DL (2011) 'Tactical Athletes': The United States Paralympic Military Programme and the mobilization of the disabled solder/athlete. Sport in Society 14(5): 553-568

Beacom A, French L and Kendall S (2016) Reframing impairment? Continuity and change in media representations of disability through the Paralympic games. International Journal of Sport Communication 9: $42-62$

Beckert K (2010) Institutional Isomorphism revisited: Convergence and divergence in institutional change. Sociological Theory 28(2): 150-166.

Berger RJ (2008) Disability and the dedicated wheelchair athlete: beyond the 'supercrip' critique. Journal of contemporary ethnography 37(6): 647-678

Briant E, Watson N and Philo G (2013) Reporting disability in the age of austerity: the changing face of media representation of disability and disabled people in the United Kigdon and the creation of new 'folk devils'. Disability \& Society 28(6): 874-889.

Cherney JL, Lindemann K and Hardin M (2015) Research in communication, disability, and sport. Communication \& Sport. 3(1): 8-26

Coffey A and Atkinson P (1996) Making sense of qualitative data. London: Sage

Cooky C and Messner M (2013) Women play sport, But not on YV: A longitudinal study of televised news media. Communication \& Sport. 1(3): 203-230.

Crow L (2014) Scroungers and Superhumans: images of disability from the summer of 2012: A visual inquiry. Journal of Visual Culture. 13(2): 168-181. 
Cutcher L and Achtel P (2017) 'Doing the brand': aesthetic labour as situated, relational performance in fashion retail. Work, Employment and Society 31(4): 675-691.

Delaney KJ (2007) Methodological dilemmas and opportunities in interviewing organizational elites. Sociology Compass. 1(1): 208-221.

DePauw K (1997) The (In)visibility of disability: cultural contexts and "sporting bodies". Quest 49: 416430.

DiMaggio P and Powell W (1983) The iron cage revisited: Institutional isomorphism and collective rationality in organizational fields. American Sociological Review 48(2): 147-160.

Ellis K (2008) 'Beyond the Aww Factor: Human interest Profiles of Paralympians and the media navigation of physical difference and social stigma'. Asia Pacific Media Educator 19: 23-35

Ellis K (2016) Disability Media Work. New York: Palgrave Macmillan

Ellis K and Goggin G (2015). Disability and the Media. Hampshire: Palgrave Macmillan

Ferguson M and Golding P (1997) Cultural studies in question. London: Sage

Freedman D (2008) The Politics of Media Policy. Cambridge: Polity.

Gee BL and Leberman SI (2011) Sports media decision making in France: How they choose what we get to see and read. International Journal of Sport Communication 4: 321-343

Giuffre E (2015) "\#IsItOk to be a celebrity (disabled) comedian? Approaching disability with Adam Hills' television program, The Last Leg'. In: Jackson D, Hodges C, Molesworth M and Scullion R (eds) 
Reframing Disability?: Media, (Dis)Empowerment, and Voice in the London Paralympics. Routledge: London. pp. 66-66.

Goodley D (2011) Disability Studies: An Interdisciplinary Introduction. London: Sage

Hardin MM and Hardin B (2008) Elite wheelchair athletes relate to sport media. In: Gilbert K and Schantz OJ (eds). The Paralympic Games: empowerment or sideshow? Maidenhead: Meyer and Meyer, pp 25-34.

Hardin MM and Hardin B (2004) The "supercrip" in sport media: Wheelchair athletes discuss hegemony's disabled hero. Sociology of Sport Online, 7(1).

Howe D (2008) The cultural politics of the Paralympic movement. London. Routledge

Author Removed (2015)

Jhally S (1989) Cultural studies and the sports/media complex. London: Sage

Johnson R, Chambers D, Raghuram P and Tincknell E (2004) The practice of cultural studies. London: Sage

Johnson R (1986) 'What is Cultural Studies Anyway?'. Social Text 16: 38-80

Liang L (2013) Television, technology and creativity in the production of a sports mega event. Media, Culture \& Society 35(4): 472-488

MacNeill M (1996) Networks: producing Olympic ice hockey for a national television audience. Sociology of Sport Journal 13: 103-24 
McRobbie A (1996) All the world's a stage, screen or magazine: when culture is the logic of late capitalism. Media, Culture \& Society 18: 335-342.

Mikecz R (2012) Interviewing elites: addressing methodological issues. Qualitative Inquiry. 18(6): 482493

Mitchell DT and Snyder SL (2015) The biopolitics of disability. Neoliberalism, ablenationalism and peripheral embodiment. Michigan: University of Michigan Press

Mladenov T (2015) Neoliberalism, postsocialism, disability. Disability \& Society 30(3): 445-459.

Pappous AS , Marcellini E and de Léséleuc E (2011) Contested issue in research on the media coverage of female paralympic athletes. Sport in Society 14(9): 1182-1191

Ofcom (2017a) Diversity and equal opportunities in television: Monitoring report on the UK broadcasting industry. Available at: https://www.ofcom.org.uk/ data/assets/pdf_file/0017/106343/diversity-televisionreport-2017.pdf (accessed 30 May 2018).

Ofcom (2017b) Guidance: Diversity in broadcasting. Available at: https://www.ofcom.org.uk/_data/assets/pdf_file/0010/108100/guidance-diversity-broadcasting.pdf (accessed 12 June 2018).

Peers D (2009) (Dis)empowering paralympic histories: absent athletes and disabling discourses. Disability \& Society 24(5): 653-665

Purdue D and Howe P (2013) Who's in and who is it? Legitimate bodies within the Paralympic Games. Sociology of Sport Journal 30(1): 24-40. 
Rice G (2010). Reflections on interviewing elites. Area 42(1): 70-75

Schantz OJ and Gilbert K (2001) 'An Ideal Misconstrued: Newspaper Coverage of the Atlanta Paralympic Games in France and Germany’. Sociology of Sport 18(1): 69-94.

Shakespeare T (1999) 'Art and lies? Representations of disability on film'. In: Corker M and French S (eds) Disability discourse. Buckingham: Open University Press. pp. 164- 172.

Shakespeare T and Watson N (1997) Defending the social model. Disability \& Society 12(2): 293-300.

Author Removed (2002)

Author Removed (2000)

Silva CF and Howe D (2012) The (in)validity of Supercrip representation of paralympic Athletes. Journal of Sport and Social Issues 36(2): 174-194.

Stoddart B (1994) Sport, television interpretation and practice reconsidered: televised golf and analytical orthodoxies. Journal of Sport and Social Issues 18(1): 76-88

Taks M (2013) Social sustainability of non-mega sport events in a global world. European Journal for Sport and Society 10(2): 121-141.

Turner BS (1996). The Body and Society: Explorations in Social Theory 2nd edn. London: Sage.

Walsh A (2015) Out of the shadows, into the light? The broadcasting legacy of the 2012 Paralympics for Channel 4. In: Jackson D, Hodges C, Molesworth M and Scullion R (eds) Reframing Disability?: Media, (Dis)Empowerment, and Voice in the London Paralympics. London: Routledge. pp. 26-36. 
Westbrook MT, Varoe L and Pennay M (1993) Attitudes towards disabilities in a multicultural society. Social Science \& Medicine 36(5): 615-623.

Whannel G (2013). On mediatization and cultural analysis. Communication \& Sport 1(1-2): 7-17.

Whannel G (1992) Fields in vision: television sport and cultural transformation. London: Routledge

\footnotetext{
${ }^{i}$ No matter how gendered. With Tepper (2000) the notion of sexual pleasure, sexualisation and aesthetic pleasing / acceptable gendered bodies within the disability studies agenda is all but missing, save perhaps for insightful accounts of Sparkes et al. (2014) who suggested narratives of disability, sport and sexuality are framed by the ideologies of heteronormativity, compulsory heterosexuality and compulsory ablebodiedness, with identities and practices outside of such conventions deemed as excess or perverse or as some sort of sexual failure.

ii The wider project integrates elite production interviews with large scale audience interviews and focus groups, archival analysis, public pedagogic forms (including a series of performances / documentary film).
} 